\title{
Child Externalizing Behavior Problems Linked to Genetic and Non-Genetic Variation in Dental Caries
}

\author{
Michael F. Lorber Amy M. Smith Slep Richard E. Heyman Walter A. Bretz \\ Department of Cariology and Comprehensive Care, New York University College of Dentistry, New York, N.Y., USA
}

\begin{abstract}
Key Words
Attention deficit - Childhood caries · Environment . Externalizing · Genetic $\cdot$ Hyperactivity $\cdot$ Impulsivity Oppositional-defiant $\cdot$ Twins
\end{abstract}

\begin{abstract}
The association of environmental and genetic variation in caries with child externalizing behavior problems (inattention, hyperactivity, impulsivity, and defiance) was studied in a sample of 239 pairs of 3- to 8-year-old impoverished Brazilian twins. It was hypothesized that externalizing problems would show a stronger positive association with environmental than genetic variation in caries. Univariate twin models were estimated to parse variation in caries into three components: additive genetic (A), shared environment (C) and non-shared environment/error (E). Age-adjusted associations between externalizing problems and each variance component were tested. Contrary to the hypothesis, modest but very consistent negative associations were found between externalizing problems and both genetic and environmental variation in caries. Mutans streptococci and sweetness preference did not explain the negative associations of caries and externalizing problems. Externalizing problems in non-medicated children were associated with less dental decay that could be explained by both genetic and environmental factors.

(c) 2014 S. Karger AG, Basel
\end{abstract}

Childhood caries is a prevalent [Satcher, 2000], multifactorial disease, with both genetic and environmental factors playing major roles in its etiology at multiple levels of influence [Bretz et al., 2005; Fisher-Owens et al., 2007]. Here we focus on child behavior problems as 'host' factors that could contribute to caries. Behavior problems such as hyperactivity, impulsivity, inattentiveness, aggression, oppositionality, and defiance - jointly known as externalizing behavior problems - are common in childhood. Clinically significant externalizing problems occur in about $14 \%$ of US children at school entry [Carter et al., 2010]; many of these children carry diagnoses of attention deficit/hyperactivity disorder (ADHD), oppositional defiant disorder and/or conduct disorder. These externalizing disorders are highly comorbid with one another [Eiraldi et al., 1997].

There are at least two reasons that child externalizing problems may put children at risk for caries. First, children with externalizing problems exhibit a tendency toward excessive appetitive, reward-seeking behaviors [Beauchaine and Gatzke-Kopp, 2012]. This proclivity may manifest in the excessive and frequent consumption of cariogenic foods and drinks, such as sodas, breakfast cereals with refined sugar, candy and desserts [Chandra et al., 2009]. Second, children with greater externalizing problems present significant behavioral management challenges for their parents. They may, for example, resist

\section{KARGER}

E-Mail karger@karger.com

www.karger.com/cre
(C) 2014 S. Karger AG, Basel

0008-6568/14/0485-0475\$39.50/0
Michael F. Lorber

Department of Cariology and Comprehensive Care New York University College of Dentistry

345 East 24th Street, New York, NY 10010 (USA)

E-Mailmfl317@nyu.edu 
their parents' attempts at enforcing regular tooth brushing or throw tantrums to gain access to sugary foods. Blomqvist et al. [2007] found less tooth brushing among children diagnosed with ADHD versus controls. Attention problems may also be associated with caries; if so, however, we suspect that it is a function of its correlation with the other aforementioned externalizing problems.

To date, associations found between externalizing problems and childhood caries are inconsistent [Broadbent et al., 2004; Blomqvist et al., 2007; Bimstein et al., 2008; Williamson et al., 2008; Hidas et al., 2011; Kohlboeck et al., 2013], notwithstanding the long range power of boyhood externalizing problems in predicting adult caries reported by Odgers et al. [2007]. We theorize that this inconsistency is due in part to genetic influences. Externalizing problems can only be expected to influence non-genetic variation in caries. Barring shared genes that cause caries and externalizing behaviors - an unlikely scenario - externalizing problems likely impact caries through environmental pathways. If this is so, associations of externalizing problems and caries in non-genetically informative designs would be attenuated by the lack of association of externalizing problems and genetic variation in caries. To address this issue, we used a twin study design and tested the associations of externalizing problems with environmental, relative to genetic, variation in child caries. We hypothesized that higher levels of externalizing problems would be more strongly associated with environmental than with genetic variation in childhood caries.

\section{Subjects and Methods}

\section{Demographic Characteristics of the Study Population}

This study was approved by the New York University (USA) and Unimontes (Brazil) Institutional Review Boards and was conducted in accordance with the ethical standards described in the 1964 Declaration of Helsinki. All parents gave informed written consent for their own and their twin children's participation. Study twins were from families of a low socioeconomic level who resided in the city of Montes Claros, State of Minas Gerais, Brazil. Water supplies of the city have fluoride levels of $<0.2 \mathrm{ppm}$, and parents reported $91 \%$ of the children having never visited a dentist. The sample consisted of 239 pairs of 3- to 8-year-old twins $($ mean $=5.03$, standard deviation $=1.53)$. Recruitment was conducted by three methods. First, twins were ascertained from a government-maintained health registry including birth data from all hospitals in the Montes Claros municipality. Families of twins were approached by health care workers and invited to participate in the study. Second, research staff conducted in person group recruitment sessions at community churches to gather information and contacts. Television advertisements were the third meth- od. Approximately $53 \%$ of the children were girls. Assessment of zygosity revealed 84 pairs of monozygotic twins and 155 pairs of dizygotic twins. Siblings from each family were randomly designated as either 'Twin 1' or 'Twin 2'.

\section{Statistical Power}

Power was determined with the BWPower program [Bakeman and McArthur, 1999]. With 239 cases and a two-tailed alpha of 0.05 , power exceeded 0.80 to detect population correlations of approximately 0.18 or greater.

\section{Zygosity Assessment}

DNA was extracted from peripheral venous blood samples. DNA marker loci were PCR-amplified using standard methods. Amplification products were detected by blood kits (QIAamp, Qiagen Inc., Valencia, Calif., USA) with an ABI-377 fluorescent sequencer and analyzed by GENESCAN 2.1 (Applied Biosystems, Foster City, Calif., USA) [Zhang et al., 2001]. Zygosity was determined by genotyping all individuals for eight highly polymorphic DNA loci (on chromosomes 2, 7, 11, 17 and 20). Individuals discordant for one or more markers were considered dizygotic.

\section{Dental Caries Examination/Variables}

Prior to the dental caries exam, twins had their teeth thoroughly brushed, flossed and dried, all supervised by a dental hygienist. Two examiners conducted dental caries examination according to National Institute of Dental and Craniofacial Research (NIDCR) criteria [Kastle et al., 1996] modified to distinguish caries lesions of chalky whitish/yellowish opaque appearance with no clinically detectable loss of substance (white spot lesions) from cavitated caries lesions. Visual assessment of cavitated and non-cavitated lesions (white spot lesions) was performed for all surfaces. Caries exams of the primary dentition were complemented by the use of digital imaging fiber-optic trans-illumination (DIFOTI; Electro-Optical Sciences, Inc., Irvington, N.Y., USA) for the interproximal surfaces if incipient lesions were present. Once a lesion was detected, its severity was determined as follows: 1 = white spot lesions; 2 = enamel lesions with loss of intact surface; 3 = dentinal lesions at initial stages of breakdown; $4=$ lesions $>2-3 \mathrm{~mm}$ into dentine. Cohen's kappa ( $\kappa)$ statistic was used to assess inter-examiner reliability for dental caries in $10 \%$ of the participants $(\kappa=0.85)$.

Summary variables were generated as follows: surface-based caries prevalence rate (SBCPR) $-100 \times$ (total number of decayed surfaces/total number of surfaces present) [Bretz et al., 1992] and SBCPRs according to lesion severity (SBCPR for white spot, initial enamel, initial dentine and deep dentinal lesions). We report on dental caries severity of lesions as externalizing behavior problems could conceivably influence staging of dental caries lesions. We hypothesize that lesion severity could be due to oral health neglect, not seeking dental care, or frequent intake of sucrose in children with externalizing problems, and therefore could be more informative for the study purposes.

\section{Mutans Streptococci Assay}

The Stripmutans ${ }^{\mathrm{TM}}$ (Orion Diagnostica, Espoo, Finland) test was employed to determine the salivary levels of mutans streptococci [Jensen and Bratthall, 1989]. Two thirds of a treated plastic strip was inserted into the mouth and rotated on the surface of the tongue about 10 times. This strip was placed into a culture vial containing a well-mixed bacitracin solution and processed accord- 
Table 1. Descriptive statistics for study measures

\begin{tabular}{|c|c|c|c|c|c|c|c|c|}
\hline & & Mean & SD & Median & $\begin{array}{l}25 \text { th } \\
\text { percentile }\end{array}$ & $\begin{array}{l}75 \text { th } \\
\text { percentile }\end{array}$ & Minimum & Maximum \\
\hline Age, years & & 5.03 & 1.53 & 5.00 & 4.00 & 6.00 & 3.00 & 8.00 \\
\hline White spot lesions ${ }^{1}$ & Twin 1 & 2.73 & 3.08 & 2.04 & 0.00 & 3.75 & 0.00 & 20.59 \\
\hline White spot lesions & Twin 2 & 2.70 & 2.76 & 2.01 & 0.00 & 4.55 & 0.00 & 13.64 \\
\hline Primary enamel lesions ${ }^{1}$ & Twin 1 & 3.49 & 2.90 & 3.41 & 1.14 & 5.68 & 0.00 & 12.00 \\
\hline Initial dentine lesions ${ }^{1}$ & Twin 1 & 3.09 & 3.33 & 2.27 & 0.00 & 4.71 & 0.00 & 17.11 \\
\hline Initial dentine lesions & Twin 2 & 2.90 & 3.61 & 2.27 & 0.00 & 4.29 & 0.00 & 26.19 \\
\hline Deep dentine lesions ${ }^{1}$ & Twin 1 & 2.44 & 4.16 & 0.00 & 0.00 & 3.33 & 0.00 & 21.98 \\
\hline Deep dentine lesions & Twin 2 & 2.15 & 3.93 & 0.00 & 0.00 & 2.42 & 0.00 & 24.71 \\
\hline Oppositional/defiant & Twin 1 & 0.52 & 0.32 & 0.50 & 0.33 & 0.67 & 0.00 & 1.50 \\
\hline Oppositional/defiant & Twin 2 & 0.51 & 0.32 & 0.50 & 0.33 & 0.67 & 0.00 & 1.67 \\
\hline Mutans streptococci & Twin 1 & 0.65 & 0.98 & 0.00 & 0.00 & 1.00 & 0.00 & 3.00 \\
\hline Mutans streptococci & Twin 2 & 0.73 & 1.02 & 0.00 & 0.00 & 1.25 & 0.00 & 3.00 \\
\hline Sweetness preference & Twin 1 & 7.21 & 2.44 & 7.00 & 6.00 & 10.00 & 0.00 & 10.00 \\
\hline Sweetness preference & Twin 2 & 7.23 & 2.47 & 7.00 & 6.00 & 10.00 & 0.00 & 10.00 \\
\hline
\end{tabular}

${ }^{1}$ SBCPRs.

ing to the manufacturer's instructions. Interpretation of Stripmu$\operatorname{tans}^{\mathrm{TM}}$ test scores using a density chart was as follows: $0-1=$ $<100,000 \mathrm{CFU} / \mathrm{ml}$ of saliva; $2=>100,000$ to $<1,000,000 \mathrm{CFU} / \mathrm{ml}$; $3=>1,000,000 \mathrm{CFU} / \mathrm{ml}$. This measure was available on a subsample of 158 and 154 siblings.

\section{Sucrose Sweetness Preference Test/Variable}

Sweetness preference was assessed by a modified version of the Sweet Preference Inventory [Birch and Sullivan, 1991] which assessed twins' preferences for five different sucrose/grape juice solutions: $0.15,0.29,0.59,0.77$ and $1.17 \mathrm{M}$. A face scale [Land and Sheperd, 1984] ranked their sweetness preference (frown $=0$, neutral $=1$, smile $=2$ ). A sucrose sweetness preference score was derived which is a composite score for the 5 solutions based on the face scale ranking (range $0-10$ ). This measure was available on a subsample of 114 and 111 siblings.

\section{Externalizing Behavior Problems Variables}

Parents completed the Swanson, Nolan, and Pelham-IV [SNAPIV; Swanson, 1992], a 28-item measure of child behavior problems. Item averages from the hyperactivity/impulsivity (mean Cronbach's $\alpha=0.69)$, inattention $(\alpha=0.70)$ and oppositional/defiant $(\alpha=0.59)$ subscales were analyzed. Each child behavior was rated numerically from $0=$ never true to $2=$ often true. The SNAP-IV has been adapted for and validated in Brazil [Mattos et al., 2006].

\section{Analytic Strategy}

Genetic and environmental variation in caries, as well as its association with externalizing problems, was estimated via univariate twin analyses (ACE models) [Neale and Cardon, 1992] in a structural equation modeling framework with Mplus version 6 software [Muthén and Muthén, 2004]. Cases with missing data were included in the estimated models using robust full information maximum likelihood (FIML) estimation and all available cases for each analysis.

\section{Results}

Descriptive statistics for all measures are presented in table 1 .

\section{Model Selection}

ACE models divide the variance in measured caries variables into three latent variance components: additive genetic (A), shared environment (C) and non-shared environment/error (E). Figure 1 depicts ACE model specifications. However, the full ACE model is not al- 
Fig. 1. Statistical approach to studying the association of externalizing behavior problems with genetic and environmental variation in caries, using the example of shared environmental variation in caries and controlling for age effects. Gray paths are measurement model paths; black paths are the associations of interest - covariation of externalizing problems and caries. Univariate twin model parameters: $\mathrm{A}$ = additive genetic effect, $\mathrm{C}=$ shared or family-wide environment effect, $\mathrm{E}=$ non-shared or childspecific environment effect. $\mathrm{mz}=$ monozygotic; $\mathrm{dz}=$ dizygotic; $\mathrm{x}, \mathrm{y}, \mathrm{z}=$ structural parameters parsing variance in observed caries into A, C, and E components, respectively; $v, w=$ covariances of each twin's externalizing behavior problems and shared environment effect; $\mathrm{U}=$ regression of caries on child age; $M=$ mean; $\operatorname{Var}=$ variance; $\mathrm{e}=$ error/residual variance. Paths with matching letters are equated. Covariances of age and externalizing behavior were also included, but are not depicted here.

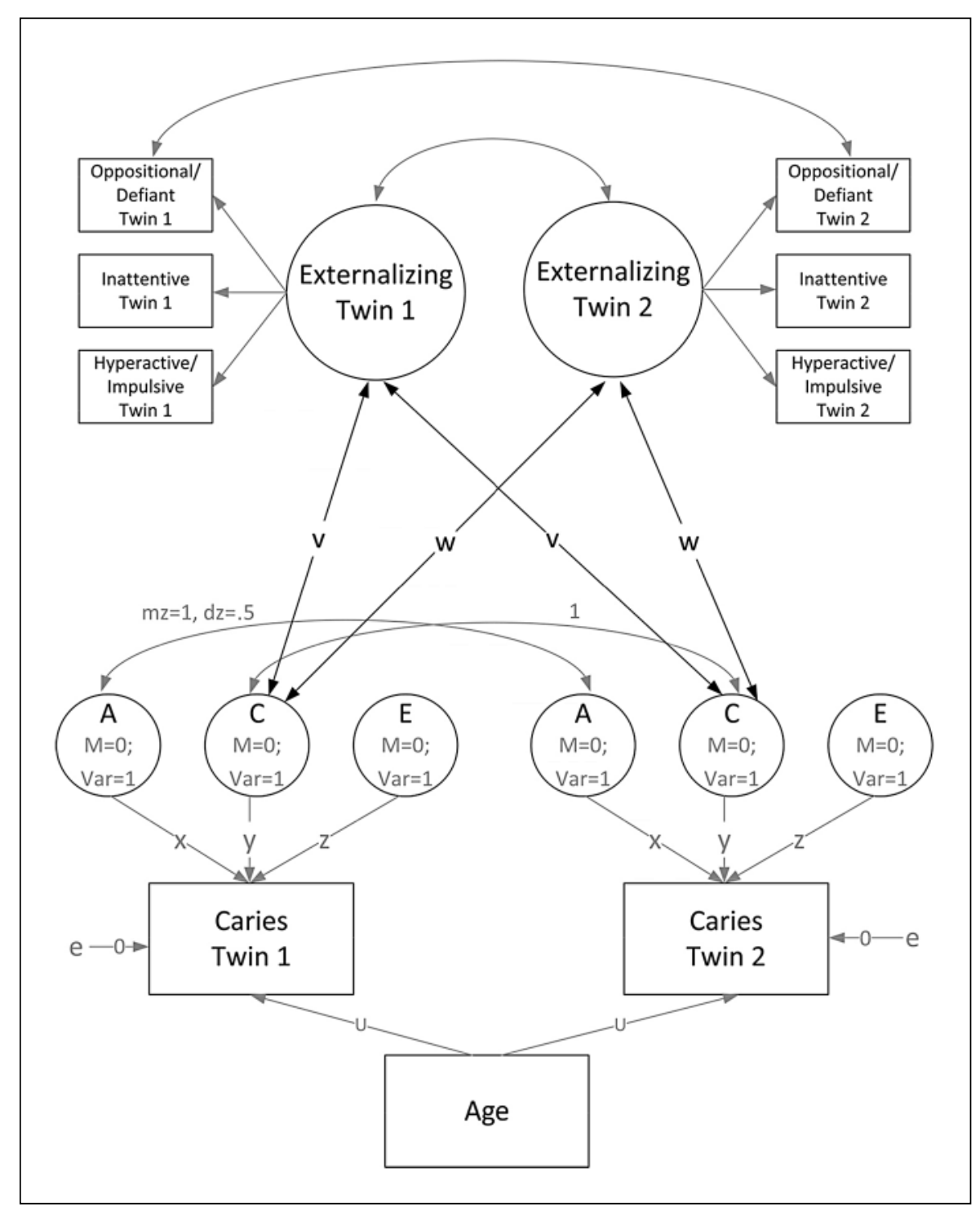

Table 2. ACE standardized estimates and fit of selected models

\begin{tabular}{lllll}
\hline $\begin{array}{l}\text { Variance } \\
\text { component }\end{array}$ & \multicolumn{4}{l}{ Caries examination variable } \\
\cline { 2 - 5 } & $\begin{array}{l}\text { white } \\
\text { spots }\end{array}$ & $\begin{array}{l}\text { initial } \\
\text { enamel }\end{array}$ & $\begin{array}{l}\text { initial } \\
\text { dentine }\end{array}$ & $\begin{array}{l}\text { deep } \\
\text { dentine }\end{array}$ \\
\hline $\mathrm{A}^{2}$ & 0.42 & 0.53 & 0.50 & - \\
$\mathrm{C}^{2}$ & - & - & - & 0.44 \\
$\mathrm{E}^{2}$ & 0.58 & 0.47 & 0.50 & 0.56 \\
$\chi^{2}$ & 15.55 & 4.99 & 3.67 & 15.89 \\
$\mathrm{p}$ & 0.03 & 0.66 & 0.82 & 0.03 \\
$\mathrm{BIC}$ & $1,377.40$ & $1,302.66$ & $1,295.68$ & $1,171.05$
\end{tabular}

$\mathrm{A}=$ Additive genetic effect; $\mathrm{C}=$ shared or family-wide environment effect; $\mathrm{E}=$ non-shared or child-specific environment effect; d.f. $=7$ in all models; $\chi^{2}=$ Satorra-Bentler scaled (robust) chi square. ways the best fit to the data. Thus, we estimated the relative model fit of $\mathrm{ACE}, \mathrm{AE}$ and $\mathrm{CE}$ models by comparing the Bayesian Information Criterion (BIC) [Schwarz, 1978] value for each model. As shown in table 2, the $\mathrm{AE}$ model was the best fit (i.e., lowest BIC) for three of the four caries variables, with heritability estimates ranging from 42 to $53 \%$. Only deep dentine lesions differed, with the CE model yielding the best fit (44\% shared environmental variation).

Externalizing problems measurement models were also evaluated, with hyperactivity/impulsivity, attention problems and oppositional/defiant scores on the SNAPIV used as joint indicators of a latent externalizing factor for each sibling. Siblings' externalizing factors and oppo- 
Table 3. Correlation of externalizing behavior problems with environmental and genetic variation in caries

\begin{tabular}{|c|c|c|c|c|c|c|c|c|c|}
\hline \multirow{3}{*}{$\begin{array}{l}\text { Variance } \\
\text { component }\end{array}$} & \multirow{3}{*}{$\begin{array}{l}\text { Predictor/ } \\
\text { twin }\end{array}$} & \multicolumn{8}{|c|}{ Caries examination variable } \\
\hline & & \multicolumn{2}{|c|}{ white spots } & \multicolumn{2}{|c|}{ initial enamel } & \multicolumn{2}{|c|}{ initial dentine } & \multicolumn{2}{|c|}{ deep dentine } \\
\hline & & $\beta^{1}$ & $\mathrm{p}$ & $\beta^{1}$ & $\mathrm{p}$ & $\beta^{1}$ & $\mathrm{p}$ & $\beta^{1}$ & $\mathrm{p}$ \\
\hline \multirow[t]{2}{*}{ A } & Ext - Twin 1 & -0.30 & 0.001 & -0.18 & 0.024 & -0.24 & 0.007 & & \\
\hline & Ext - Twin 2 & -0.21 & 0.017 & -0.15 & 0.088 & -0.18 & 0.051 & & \\
\hline \multirow[t]{2}{*}{$\mathrm{C}$} & Ext - Twin 1 & & & & & & & -0.24 & 0.008 \\
\hline & Ext - Twin 2 & & & & & & & -0.26 & 0.010 \\
\hline \multirow[t]{2}{*}{$\mathrm{E}$} & Ext - Twin 1 & -0.23 & 0.003 & -0.17 & 0.022 & -0.22 & 0.008 & -0.20 & 0.007 \\
\hline & Ext - Twin 2 & -0.16 & 0.025 & -0.14 & 0.083 & -0.17 & 0.043 & -0.22 & 0.008 \\
\hline
\end{tabular}

\footnotetext{
${ }^{1}$ Associations are standardized covariances; $\mathrm{A}=$ additive genetic effect; $\mathrm{C}=$ shared or family-wide environment effect; $\mathrm{E}$ = non-shared or child-specific environment effect; Ext = externalizing behavior problems; age effects on manifest caries variables were controlled for in all cases.
}

sitional/defiant residual terms were, respectively, allowed to covary. Model fit was good $\left[\chi^{2}(7)=12.51, \mathrm{p}=0.085\right.$, Comparative Fit Index $=0.98$, Tucker-Lewis index $=0.96$, Root Mean Square Error of Approximation = 0.06] and standardized factor loadings ranged from 0.48 to 0.79 $(\mathrm{p}<0.001)$.

\section{Association of Caries and Externalizing Problems}

As shown in figure 1, genetic and environmental variance in caries was studied in relation to externalizing problems by combining the best fit (AE and $\mathrm{CE}$ ) models and externalizing problems measurement model, with separate analyses for each caries variable. Each caries variable was also regressed on child age, which itself was allowed to correlate with externalizing problems.

The associations of each sibling's externalizing problems with $\mathrm{A}, \mathrm{C}$ and $\mathrm{E}$ components were the primary hypothesis tests and are reported in table 3 . In contrast to the expected positive associations of caries and externalizing problems, negative caries-externalizing associations were consistently found for both genetic (A) and environmental (C, E) terms. The 16 associations computed ranged from -0.14 to -0.30 and 13 of them were statistically significant.

\section{Post hoc Analyses}

To investigate mediating factors that might explain the unexpected negative association of externalizing problems and caries, we tested the association of externalizing problems with mutans streptococci and sweetness preference variables. The externalizing-mutans streptococci as-

Child Behavior Problems and Childhood Caries sociations were non-significant $(\beta=-0.08$ and 0.01 for Twin 1 and 2, respectively, n.s.). There was some evidence of an association of sweetness preference and externalizing problems. This association was tested only on those with complete data, due to the very high rate of missing sweetness preference data - too high to yield stable estimates under FIML. A composite externalizing problems score was calculated for each twin as the average of $\mathrm{z}$ scores across each SNAP-IV subscale. The correlation of this composite with sweetness preference was significant for the 'Twin 2' set of children $[\mathrm{r}(107)=0.23, \mathrm{p}=0.015$ ], but not for the 'Twin 1' set of children $[\mathrm{r}(110)=0.08$, n.s.]. However, sweetness preference was not correlated with any caries variable, ruling out the possibility of a mediated pathway from externalizing problems to caries via sweetness preference.

\section{Discussion}

Our initial hypothesis that child externalizing problems would be more strongly associated with environmental than with genetic variation in childhood caries was not supported. Our results suggest that there are both genetic and environmental contributions to dental caries and that each is modestly correlated with child externalizing problems. Yet child externalizing problems were associated with less dental decay.

We considered several explanations for the negative externalizing-caries associations. Thus far, the literature on the association of child externalizing problems 
with caries has been quite mixed, with positive, negative and null findings. Our findings are the most similar to those of Hidas et al. [2011], who reported that nonmedicated children with ADHD had marginally significantly $(p=0.08)$ fewer carious lesions compared with control children with the effect size for the difference $(\mathrm{r}=-0.24 ; \mathrm{p}=0.08)$ very consistent with those that we report. In contrast, Grooms et al. [2005] did not find a significant difference in primary tooth caries in nonmedicated children with ADHD compared with control children $(r=-0.06)$. Medication data were not collected in the present sample; however, participants were drawn from an extremely impoverished population with very poor access to health care. Accordingly, we are certain that the vast majority of study children, if not all, were not medicated. Taking our findings together with those of Hidas et al. [2011] and Grooms et al. [2005], it seems possible that medication changes the association of externalizing problems and caries, with positive associations a byproduct of psychiatric medication. Children on medication may experience changes in appetite leading to increased sucrose intake (perhaps due to increased parental leniency in the face of the side effect of appetite suppression), thus explaining increased caries rates in children with externalizing behavioral problems. These notions have received contrasting and inconsistent support in the literature [Friedlander et al., 2007; Grooms et al., 2005; Hidas et al., 2011] and need further substantiation.

If the association of externalizing problems and caries among non-medicated children is truly a negative one, why might that be? Recent evidence suggests that levels of the immune molecule secretory immunoglobulin A (SIgA) are elevated in children with behavior problems [Keller et al., 2010]. The critical importance of salivary SIgA in children's mucosal resistance to cariogenic bacteria is well recognized [Law et al., 2007]. If salivary SIgA was elevated in children with greater externalizing problems in the present study, their mouths may have been less hospitable environments for cariogenic bacteria, resulting in less decay - a possibility offered tentatively, pending empirical substantiation.

Parental efforts to reduce child sugar consumption as a method of controlling problem behavior might be a viable alternative explanation for the negative externalizing-decay associations we found. Parents commonly misattribute problem child behaviors such as ADHD to sugar intake and believe that reducing sugar consumption is an effective treatment [Johnston and Freeman, 2002]. If the parents of more behaviorally challenging children in the present study restricted their children's sugar consumption, lower decay rates would be an expected consequence. We were unable to evaluate this hypothesis, as our study included an objective measure of sucrose sweetness preference, but not sugar consumption itself.

Additional as of yet unidentified moderators and mediators may also be at play. We assessed, but did not find support for, the mediation of the externalizing problems-caries link by sucrose sweetness preference and mutans streptococci salivary levels. Table 1 clearly shows that the vast majority of twins had a predilection for sucrose sweetness. The levels of infection by mutans streptococci were high in about $45 \%$ of the cohort and low in about $55 \%$ of our cohort (data not shown). As we employed a rapid and simple assay to assess salivary levels of mutans streptococci, we may have missed other bacterial species [see Peterson et al., 2013] that explained the negative association of externalizing problems and caries.

The association of externalizing problems and caries may also depend on children's genetic endowment, which is population-dependent. In ACE modeling, such gene $\times$ environment interactions count toward the A term, inflating the apparent genetic main effects. Such 'phantom heritability' [Zuk et al., 2012] is a well-known problem in behavior genetics and may conceivably also influence studies of dental caries heritability estimates. It is premature at this point to speculate which genes may be involved, but evidence for gene $x$ environment interactions is rapidly accumulating for behavior problems and should be considered in studies of dental caries and associated behavior problems.

Collectively, our results have shown that child externalizing problems were associated with less dental decay that could be explained by both genetic and environmental factors. These unanticipated findings, considered in concert with prior findings and theory, suggest several novel hypotheses that are in need of empirical evaluation. Finally, generalization to child populations that are not as impoverished as the present study sample is not assured.

\section{Acknowledgements}

This study was supported by NIH/NIDCR grant DE15351 (W.A. Bretz). We acknowledge contributions for this study of Drs. Patricia Corby, Michael Vanyukov and Brian Maher. We further thank Drs. Svetlana Rivilis, Bruce Ellis, Jay Belsky, Tom Boyce, Marco Del Giudice, Alexander Weiss and Leslie Boyer for their valuable feedback. 


\section{Author Contribution}

M.F. Lorber: conceptualization, data analysis, manuscript preparation; A.M.S. Slep: conceptualization, manuscript preparation; R.E. Heyman: conceptualization, manuscript preparation; W.A. Bretz: conceptualization, data collection, manuscript preparation.

\section{Disclosure Statement}

The authors do not report any conflicts of interest related to the present research.

\section{References}

Bakeman R, McArthur D: Determining the power of multiple regression analyses both with and without repeated measures. Behav Res Methods Instrum Comput 1999;31:150-154.

Beauchaine TP, Gatzke-Kopp LM: Instantiating the multiple levels of analysis perspective in a program of study on externalizing behavior. Dev Psychopathol 2012;24:1003-1018.

Bimstein E, Wilson J, Guelmann M, Primosch R: Oral characteristics of children with attention-deficit hyperactivity disorder. Spec Car Dentist 2008;28:107-110.

Birch LL, Sullivan SA: Measuring children's food preferences. J Sch Health 1991;61:212-214.

Blomqvist M, Holmberg K, Fernell E, Ek U, Dahllöf G: Dental caries and oral health behavior in children with attention deficit hyperactivity disorder. Eur J Oral Sci 2007;115: 186-191.

Bretz WA, Corby PM, Schork NJ, Robinson MT, Coelho M, Costa S, Melo Filho MR, Weyant RJ, Hart TC: Longitudinal analysis of heritability for dental caries traits. J Dent Res 2005; 84:1047-1051.

Bretz WA, Djahjah C, Almeida R, Hujoel PP, Loesche WJ: Relationship of microbial and salivary parameters with dental caries in Brazilian pre-school children. Community Dent Oral Epidemiol 1992;20:261-264.

Broadbent JM, Ayers KM, Thomson WM: Is attention-deficit hyperactivity disorder a risk factor for dental caries? A case-control study. Caries Res 2004;38:29-33.

-Carter AS, Wagmiller RJ, Gray SA, McCarthy KJ, Horwitz SM, Briggs-Gowan MJ: Prevalence of DSM-IV disorder in a representative, healthy birth cohort at school entry: sociodemographic risks and social adaptation. J Am Acad Child Adolesc Psychiatry 2010;49:686698.

Chandra P, Anandakrishna L, Ray P: Caries experience and oral hygiene status of children suffering from attention deficit hyperactivity disorder. J Clin Pediatr Dent 2009;34:25-29.

Eiraldi RB, Power TJ, Nezu CM: Patterns of comorbidity associated with subtypes of attention-deficit/hyperactivity disorder among 6to 12-year-old children. J Am Acad Child Adolesc Psychiatry 1997;36:503-514.
Fisher-Owens SA, Gansky SA, Platt LJ, Wein- Law V, Seow WK, Townsend G: Factors influenctraub JA, Soobader MJ, Bramlett MD, Newacheck PW: Influences on children's oral health: a conceptual model. Pediatrics 2007; 120:e510-e520.

Friedlander AH, Yagiela JA, Mahler ME, Rubin R: The pathophysiology, medical management and dental implications of adult attentiondeficit/hyperactivity disorder. J Am Dent Assoc 2007;138:475-482.

Grooms MT, Keels MA, Roberts MW, McIver FT: Caries experience associated with attentiondeficit/hyperactivity disorder. J Clin Pediatr Dent 2005;30:3-7.

Hidas A, Noy AF, Birman N, Shapira J, Matot I, Steinberg D, Moskovitz M: Oral health status, salivary flow rate and salivary quality in children, adolescents and young adults with ADHD. Arch Oral Biol 2011;56:1137-1141.

Jensen B, Bratthall D: A new method for the estimation of mutans streptococci in human saliva. J Dent Res 1989;68:468-471.

Johnston C, Freeman W: Parents' beliefs about ADHD: implications for assessment and treatment. ADHD Rep 2002;10:6-9.

Kastle L, Selwitz R, Oldakeki R, Brunelle JA, Winn DM, Brown LJ: Coronal caries in the primary dentition and permanent dentition of children and adolescents 1-17 years of age: United States, 1988-1991. J Dent Res 1996;75: 631-641.

Keller PS, El-Sheikh M, Vaughn B, Granger DA: Relations between mucosal immunity and children's mental health: the role of child sex. Physiol Behav 2010;101:705-712.

Kohlboeck G, Heitmueller D, Neumann C, Tiesler C, Heinrich J, Heinrich-Weltzien R, Hickel R, Koletzko S, Herbarth O, Kühnisch J; GINIplus Study Group, LISAplus Study Group: Is there a relationship between hyperactivity/inattention symptoms and poor oral health? Results from the GINIplus and LISAplus study. Clin Oral Investig 2013;17: 1329-1338.

Land D, Sheperd R: Scaling and ranking methods; in Piggott J (ed): Sensory Analysis of Foods. London, Elsevier, 1984, pp 141-177. ing oral colonization of mutans streptococci in young children. Aust Dent J 2007;52:93100.

Mattos P, Serra-Pinheiro MA, Rohde LA, Pinto D: A Brazilian version of the MTA-SNAP-IV for evaluation of symptoms of attention-deficit/hyperactivity disorder and oppositionaldefiant disorder. Rev Psiquiatr Rio Grande do Sul 2006;28:290-297.

Muthén LK, Muthén BO: Mplus user's guide (3rd ed.). Los Angeles, Author, 2004.

$>$ Neale MC, Cardon LR: Methodology for Genetic Studies of Twins and Families. Dordrecht, Kluwer Academic Publishers, 1992.

Odgers CL, Caspi A, Broadbent JM, Dickson N, Hancox RJ, Harrington H, Poulton R, Sears MR, Thomson WM, Moffitt TE: Prediction of differential adult health burden by conduct problem subtypes in males. Arch Gen Psychiatry 2007;64:476-484.

Peterson SN, Snesrud E, Liu J, Killian M, Schork NJ, Bretz WA: The dental plaque microbiome in health and disease. PLoS One 2013;8: e58487.

Satcher D: Oral health in America: a report of the Surgeon General. Rockville, National Institute of Dental and Craniofacial Research, National Institutes of Health, 2000.

Schwarz G: Estimating the dimension of a model. Ann Stat 1978;6:461-464. terventions for ADD Students. Irvine, K.C. Publications, 1992.

Williamson R, Oueis H, Casamassimo PS, Thikkurissy SL: Association between early childhood caries and behavior as measured by the Child Behavior Checklist. Pediatr Dent 2008; 30:505-509.

Zhang Y, Lundgren T, Renvert S, Tatakis DN, Firatli E, Uygur C, Hart PS, Gorry MC, Marks JJ, Hart TC: Evidence of a founder effect for four cathepsin $\mathrm{C}$ gene mutations in PapillonLefèvre syndrome patients. J Med Genet 2001; 38:96-101.

Zuk O, Hechter E, Sunyaev SR, Lander ES: The mystery of missing heritability: genetic interactions create phantom heritability. Proc Natl Acad Sci USA 2012;109:1193-1198.
Swanson JM: School-Based Assessments and In- 